\title{
In Vitro Anti-tumor Activity of Azulene Amide Derivatives
}

\author{
TOSHIKI WADA ${ }^{1 *}$, RYOTA MARUYAMA $^{1 *}$, YUTA IRIE $^{1}$, MASASHI HASHIMOTO $^{1}$, \\ HIDETSUGU WAKABAYASHI ${ }^{1}$, NORIYUKI OKUDAIRA ${ }^{2}$, \\ YOSHIHIRO UESAWA ${ }^{3}$, HAJIME KAGAYA ${ }^{3}$ and HIROSHI SAKAGAMI ${ }^{4}$ \\ ${ }^{1}$ Faculty of Science, Josai University, Saitama, Japan; \\ ${ }^{2}$ Division of Pharmacology, Meikai University School of Dentistry and \\ ${ }^{4}$ Meikai University Research Institute of Odontology (M-RIO), Saitama, Japan; \\ ${ }^{3}$ Department of Clinical Pharmaceutics, Meiji Pharmaceutical University, Tokyo, Japan
}

\begin{abstract}
Background/Aim: There exist few research articles regarding the anticancer activity of azulene-related compounds. We investigated here the relative cytotoxicity of 10 azulene amide derivatives against cancer and normal cells. Materials and Methods: Cytotoxicity against four human oral squamous cell carcinoma (OSCC) cell lines and three human oral normal cells (gingival fibroblasts, periodontal ligament fibroblasts and pulp cells) was determined by the 3-(4,5-dimethylthiazol-2-yl)-2,5diphenyltetra-zolium bromide method. Antitumor activity was evaluated by tumor-specificity (TS) (ratio of mean 50\% cytotoxic concentration $\left(C_{50}\right)$ against normal cells to that against OSCC cell lines) and potency-selectivity expression (PSE) (ratio of TS to $C C_{50}$ against tumor cells). Apoptosisinducing activity was evaluated by cleavage of poly $A D P$ ribose polymerase and caspase-3 with western blot analysis. Results. N-Propylguaiazulenecarboxamide [1] showed the highest TS and PSE values, compared to that of doxorubicin, and induced apoptosis in two OSCC cell lines. QSAR analysis demonstrated that their tumor-specificity of azulene amide derivatives was correlated with hydrophobicity and molecular shape. Conclusion: Compound [1] can be considered as a lead compound for manufacturing new anticancer drug candidates.
\end{abstract}

This article is freely accessible online.

*These Authors contributed equally to this work.

Correspondence to: Hidetsugu Wakabayashi, Faculty of Science, Josai University, 1-1 Keyakidai, Sakado, Saitama 350-0295, Japan. Tel: +81 492717959, Fax: +81 492717985, e-mail: hwaka@josai.ac.jp/ sakagami@dent.meikai.ac.jp

Key Words: Azulene amides, cytotoxicity, tumor specificity, hydrophobicity, molecular shape, apoptosis.
Azulene, an isomer of naphthalene, has a dipole moment and a resonance energy with intermediate values between that of benzene and naphthalene, and is considerably more reactive, when compared with two arenes. Azulene gargle has been reported to reduce the incidence of postoperative sore caused by general anesthesia (1). Azulene sulfonate inhibited the capsaicin-induced plasma exudation in the pharyngeal mucosa of the rat (2). 6-Isopropyl-3-[4-(4-chlorophenylsulfonylamino)butyl]azulene-1-sulfonic acid sodium salt (KT2-962), thromboxane A receptor antagonist, significantly reduced the incidence of ventricular fibrillation during the ischemic period and also myocardial infarct size, possibly by its direct free radical scavenging properties (3). Guaiazulene, a lipophilic azulene derivative, protected rats from paracetamol hepatotoxicity via its antioxidant activity (4) and its inhibitory effect on some cytochrome P450 activities (5). However, there is a limited number of studies that investigated the cytotoxicity of guaiazulene against human leukemic cell lines (HL-60, K562) $(6,7)$, freshly prepared rat neuron cells, neuroblastoma cell lines (8) and human gingival fibroblasts (9).

In order to search for tumor-selective guaiazulene derivatives, we have synthesized ten azulene amide derivatives (Figure 1) and investigated their anticancer activity. Since previous reports have shown that anticancer agents induce apoptosis in clinical cancer tissues (10), we also investigated the induction of apoptosis by these compounds.

\section{Materials and Methods}

Materials. The following chemicals and reagents were obtained from the indicated companies: Dulbecco's modified Eagle's medium (DMEM) from GIBCO BRL, Grand Island, NY, USA; fetal bovine serum (FBS), 3-(4,5-dimethylthiazol-2-yl)-2,5-diphenyltetrazolium bromide (MTT), doxorubicin-HCl (DXR) from Sigma-Aldrich Inc. (St. Louis, MO, USA); dimethyl sulfoxide (DMSO) from Wako Pure Chem. Ind., Osaka, Japan; Culture plastic dishes and plates (96-well) were purchased from Becton Dickinson (Franklin Lakes, NJ, USA). 
Protease and phosphatase inhibitors were purchased from Roche Diagnostics (Tokyo, Japan). Antibodies against cleaved caspase-3 (Cell Signaling Technology Inc., Beverly, MD, USA), PARP (Cell Signaling Technology Inc., Beverly, MD, USA) and glyceraldehyde 3-phosphate dehydrogenase (GAPDH), Trevigen, Gaithersburg, MD, USA) were used as primary antibodies. As secondary antibodies, $\alpha-$ rabbit IgG (DAKO, Tokyo, Japan) antibodies, which were conjugated with horseradish peroxidase, were used.

Synthesis of alklyaminogroups. $N$-propylguaiazulenecarboxamide [1], $N$-butylguaiazulenecarboxamide [2], $N$-pentylguaiazulenecarboxamide [3], $N$-(2-hydroxyethyl)guaiazulenecarboxamide [4], $N$-(3-hydroxypropyl)guaiazulenecarboxamide [5], $N$-(2-methoxyethyl)guaiazulenecarboxamide [6], $\mathrm{N}$-(3-methoxypropyl)guaiazulenecarboxamide [7], $\mathrm{N}$-(2-aminopropyl)guaiazulenecarboxamide [8], $\mathrm{N}$-(3-aminobutyl)guaiazulenecarboxamide [9], $N$-(2-(2-aminoethoxy)ethoxyethyl)guaiazulenecarboxamide [10] were synthesized, according to previous reports (11-14). All compounds were dissolved in DMSO at $40 \mathrm{mM}$ and stored at $-20^{\circ} \mathrm{C}$ before use.

Cell culture. HGF, HPLF and HPC cells, established from the first premolar tooth extracted from the lower jaw of a 12-year-old girl (15) and OSCC cell lines (Ca9-22, HSC-2, HSC-3, HSC-4), purchased from Riken Cell Bank, Tsukuba, Japan, were cultured at $37^{\circ} \mathrm{C}$ in DMEM supplemented with $10 \%$ heat-inactivated FBS, 100 units $/ \mathrm{ml}$, penicillin $\mathrm{G}$ and $100 \mu \mathrm{g} / \mathrm{ml}$ streptomycin sulfate under a humidified $5 \% \mathrm{CO}_{2}$ atmosphere. HGF, HPLF and HPC at 12 20 population doubling level (PDL) were used in the present study.

Assay for cytotoxic activity. Cells were inoculated at $2 \times 10^{3}$ cells $/ 0.1 \mathrm{ml}$ in a 96-microwell plate (Becton Dickinson Labware, Franklin Lakes, NJ, USA). After $48 \mathrm{~h}$, the medium was removed by suction with an aspirator and replaced with $0.1 \mathrm{ml}$ of fresh medium containing different concentrations of the test compounds. Control cells were treated with the same amounts of DMSO present in each diluent solution. Cells were incubated for $48 \mathrm{~h}$ and the relative viable cell number was then determined by the MTT method. In brief, the treated cells were incubated for another $2 \mathrm{~h}$ in fresh culture medium containing $0.2 \mathrm{mg} / \mathrm{ml}$ MTT. Cells were then lysed with $0.1 \mathrm{ml}$ of DMSO and the absorbance at $560 \mathrm{~nm}$ of the cell lysate was determined using a microplate reader (Infinite F 50 R, TECAN, Kawasaki, Japan). The $\mathrm{CC}_{50}$ was determined from the dose-response curve of triplicate samples.

Calculation of tumor-selectivity index (TS). TS was calculated using the following equation: $\mathrm{TS}=$ mean $\mathrm{CC}_{50}$ against three normal oral cells/mean $\mathrm{CC}_{50}$ against OSCC cell lines [(D/B) in Table I] (16). Since both Ca9-22 and HGF cells were derived from the gingival tissue (17), the relative sensitivity of these cells was also compared [(C/A) in Table I]. We did not use human normal oral keratinocytes for tumorspecificity assay, since many anticancer drugs showed potent cytotoxicity against normal keratinocytes by inducing apoptosis (18).

Calculation of potency-selectivity expression (PSE). PSE was calculated using the following equation: $\mathrm{PSE}=\mathrm{TS} / \mathrm{CC}_{50}$ against tumor cells $\times 100(16)$ [that is, $\left(\mathrm{D} / \mathrm{B}^{2}\right) \times 100(\mathrm{HGF}, \mathrm{HPLF}, \mathrm{HSC} v s$.

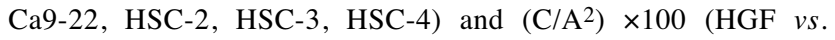
Ca9-22 in Table I).

Western blot analysis. The cells were washed with phosphate-buffered saline (PBS) and re-suspended in $50 \mathrm{mM}$ Tris- $\mathrm{HCl}$ (pH 7.6), $150 \mathrm{mM}$ $\mathrm{NaCl}, 1 \mathrm{mM}$ EDTA, $0.1 \%$ sodium dodecyl sulfate (SDS), $0.5 \%$

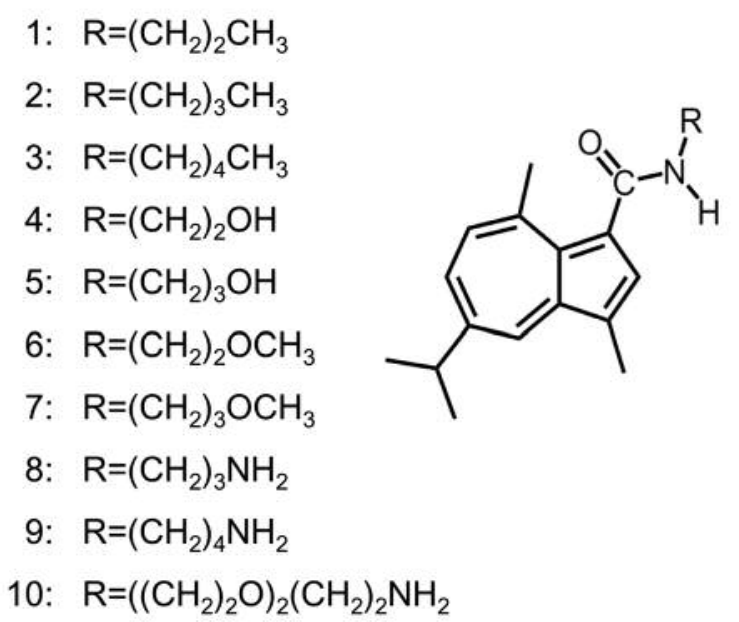

Figure 1. Structure of azulene amide derivatives.

deoxycholic acid, 1\% NP-40 and protease inhibitors (RIPA buffer). After ultrasonication using Bioruptor (UCD-250; Cosmo Bio, Tokyo, Japan) for $12.5 \mathrm{~min}$ (10 $\mathrm{sec}$ on, $20 \mathrm{sec}$ off) at the middle level of output $(250 \mathrm{~W})$ at $4{ }^{\circ} \mathrm{C}$, the soluble cellular extracts were recovered after centrifugation for $10 \mathrm{~min}$ at $16,000 \times \mathrm{g}$. The protein concentration of each sample was determined using the BCA Protein Assay Reagent Kit (Thermo Fisher Scientific, Waltham, MA, USA) and cell extracts were subjected to western blot (WB) analysis. The blots were probed with the primary antibody followed by a horseradish peroxidaseconjugated secondary antibody. The immune complexes were visualized using Pierce Western Blotting Substrate Plus (Thermo Fisher Scientific). WB results were documented and quantified using ImageQuant LAS 500 (GE Healthcare, Tokyo, Japan) (19).

Calculation of chemical descriptors. Since the $\mathrm{CC}_{50}$ values had a distribution pattern close to a logarithmic normal distribution, we used the $\mathrm{pCC}_{50}$ (i.e., the $-\log \mathrm{CC}_{50}$ ) for the comparison of the cytotoxicity between the compounds. The mean $\mathrm{pCC}_{50}$ values for normal cells and tumor cell lines were defined as $\mathrm{N}$ and $\mathrm{T}$, respectively (19).

The 3D-structure of each chemical structure (drawn by Marvin Sketch ver 16, ChemAxon, Budapest, Hungary, http://www. chemaxon.com) was optimized by CORINA Classic (Molecular Networks GmbH, Nürnberg, Germany) with partial charge calculations (amber-10: EHT) in Molecular Operating Environment (MOE) version 2015.1001 (Chemical Computing Group Inc., Quebec, Canada). The number of structural descriptors calculated from MOE after the elimination of overlapped descriptors was 297.

Eighteen MOE descriptors (20) listed in Table II were significantly correlated with T, N and T-N. Since the use of Dragon descriptors produced heavy overlapping of similar descriptors that showed higher correlation with $\mathrm{T}, \mathrm{N}$ and $\mathrm{T}-\mathrm{N}$, and therefore correlation diagrams were plotted using MOE descriptors.

Statistical treatment. Each experimental value is expressed as the mean \pm standard deviation (SD) of triplicate or quadruplicate measurements. The relation among cytotoxicity, tumor specificity 
Table I. Cytotoxicity of azulene amide derivatives and doxorubicin against human oral squamous cell carcinoma (OSCC) cell lines and human oral normal cells.

\begin{tabular}{|c|c|c|c|c|c|c|c|c|c|c|c|c|c|c|c|}
\hline & \multicolumn{11}{|c|}{$\mathrm{CC}_{50}(\mu \mathrm{M})$} & \multirow{2}{*}{\multicolumn{2}{|c|}{$\mathrm{TS}$}} & \multirow{2}{*}{\multicolumn{2}{|c|}{ PSE }} \\
\hline & \multicolumn{6}{|c|}{ Human oral squamous cell carcinoma cell lines } & \multicolumn{5}{|c|}{ Human normal oral cells } & & & & \\
\hline & $\begin{array}{c}\text { Ca-22 } \\
\text { (A) }\end{array}$ & HSC-2 & HSC-3 & HSC-4 & $\begin{array}{l}\text { Mean } \\
\text { (B) }\end{array}$ & SD & $\begin{array}{c}\text { HGF } \\
\text { (C) }\end{array}$ & HPLF & HPC & $\begin{array}{l}\text { Mean } \\
\text { (D) }\end{array}$ & SD & $(\mathrm{D} / \mathrm{B})$ & $(\mathrm{C} / \mathrm{A})$ & $\begin{array}{c}\left(\mathrm{D} / \mathrm{B}^{2}\right) \\
\times 100\end{array}$ & $\begin{array}{c}\left(\mathrm{C} / \mathrm{A}^{2}\right) \\
\times 100\end{array}$ \\
\hline \multicolumn{16}{|c|}{$<$ Exp. I $>$} \\
\hline 1 & 14.5 & 12.6 & 6.2 & $>400$ & $>108$ & 194.5 & $>400$ & $>396$ & $>400$ & $>399$ & 2.2 & $><3.7$ & $>27.7$ & $><34$ & $>191.6$ \\
\hline 2 & $>400$ & 267.7 & $>400$ & $>400$ & $>367$ & 66.1 & $>400$ & $>365$ & $>400$ & $>388$ & 20.4 & $><1.1$ & $><1.0$ & $><0.3$ & $><0.3$ \\
\hline 3 & $>392$ & 285.8 & $>400$ & $>400$ & $>369$ & 55.8 & $>400$ & $>400$ & $>400$ & $>400$ & & $><1.1$ & $><1.0$ & $><0.3$ & $><0.3$ \\
\hline 4 & 146.0 & 187.1 & 103.3 & 132.1 & 142.1 & 34.9 & 322.5 & 282.4 & 324.2 & 309.7 & 23.7 & 2.2 & 2.2 & 1.5 & 1.5 \\
\hline 5 & 91.0 & 95.9 & 215.7 & 102.5 & 126.3 & 59.8 & 291.0 & 274.1 & 296.9 & 287.3 & 11.9 & 2.3 & 3.2 & 1.8 & 3.5 \\
\hline 6 & 64.1 & 55.4 & 48.8 & 92.5 & 65.2 & 19.3 & 272.9 & 301.1 & 269.3 & 281.1 & 17.4 & 4.3 & 4.3 & 6.6 & 6.6 \\
\hline 7 & 44.3 & 50.0 & 28.4 & 58.4 & 45.3 & 12.7 & 162.7 & 204.6 & 220.7 & 196.0 & 29.9 & 4.3 & 3.7 & 9.6 & 8.3 \\
\hline 8 & 34.5 & 47.2 & 20.4 & 20.5 & 30.6 & 12.9 & 55.9 & 54.3 & 48.0 & 52.7 & 4.2 & 1.7 & 1.6 & 5.6 & 4.7 \\
\hline 9 & 36.0 & 53.6 & 20.6 & 20.4 & 32.7 & 15.8 & 45.1 & 49.9 & 28.2 & 41.1 & 11.4 & 1.3 & 1.3 & 3.9 & 3.5 \\
\hline 10 & 36.0 & 63.9 & 25.7 & 42.7 & 42.1 & 16.2 & 68.6 & 76.2 & 75.5 & 73.4 & 4.2 & 1.7 & 1.9 & 4.1 & 5.3 \\
\hline DXR & 0.5 & 0.2 & 0.3 & 1.0 & 0.5 & 0.4 & 2.1 & 282.8 & 386.2 & 223.7 & 198.7 & 448.1 & 4.1 & 89778.6 & 801.5 \\
\hline \multicolumn{16}{|c|}{$<$ Exp. II $>$} \\
\hline 1 & 17.9 & 18.7 & 14.2 & 4.4 & 13.8 & 6.6 & $>400$ & $>400$ & $>400$ & $>400$ & 0.0 & $>28.9$ & $>22.3$ & $>209.1$ & $>124.8$ \\
\hline 2 & $>400$ & 270.6 & 268.6 & 4.1 & $>235.8$ & 166.3 & $>400$ & 376.7 & $>400$ & $>392$ & 13.5 & $><1.7$ & $><1$ & $><0.7$ & $><0.3$ \\
\hline 3 & $>400$ & $>400$ & 281.4 & 4.5 & $>271.5$ & 186.6 & $>400$ & 268.7 & $>400$ & $>356$ & 75.8 & $>1.3$ & $><1$ & $>0.5$ & $>0.3$ \\
\hline 4 & 83.3 & 93.6 & 46.8 & 2.9 & 56.6 & 41.1 & 252.7 & 251.2 & 275.0 & 259.6 & 13.3 & 4.6 & 3.0 & 8.1 & 3.6 \\
\hline 5 & 148.2 & 133.6 & 145.4 & 95.1 & 130.6 & 24.5 & 228.6 & 297.7 & 273.6 & 266.7 & 35.1 & 2.0 & 1.5 & 1.6 & 1.0 \\
\hline 6 & 60.6 & 75.0 & 36.0 & 77.4 & 62.3 & 19.0 & 198.7 & 293.7 & 260.1 & 250.8 & 48.2 & 4.0 & 3.3 & 6.5 & 5.4 \\
\hline 7 & 46.5 & 62.2 & 30.1 & 38.5 & 44.3 & 13.7 & 260.2 & 259.4 & 166.4 & 228.7 & 53.9 & 5.2 & 5.6 & 11.6 & 12.0 \\
\hline 8 & 45.0 & 71.3 & 36.7 & 45.5 & 49.6 & 15.0 & 47.6 & 53.7 & 71.2 & 57.5 & 12.2 & 1.2 & 1.1 & 2.3 & 2.4 \\
\hline 9 & 37.6 & 48.8 & 26.6 & 35.4 & 37.1 & 9.1 & 39.8 & 36.8 & 44.9 & 40.5 & 4.1 & 1.1 & 1.1 & 2.9 & 2.8 \\
\hline 10 & 148.0 & 224.4 & 141.6 & 166.8 & 170.2 & 37.7 & 271.8 & 185.1 & 283.0 & 246.6 & 53.6 & 1.4 & 1.8 & 0.9 & 1.2 \\
\hline DXR & 16.1 & 15.4 & 5.5 & 136.3 & 43.3 & 62.2 & 17.1 & 324.8 & $>400$ & $>247.3$ & 202.9 & $>5.7$ & 1.1 & $>13.2$ & 6.6 \\
\hline \multicolumn{16}{|c|}{ (Exp. III> } \\
\hline 1 & 7.5 & 14.7 & 4.8 & 14.6 & 10.4 & 5.0 & $>400$ & 385.9 & 368.8 & $>384.9$ & 15.6 & $>37.0$ & $>53.6$ & $>356.1$ & $>717.3$ \\
\hline 2 & $>400$ & $>400$ & $>400$ & 344.9 & $>386.2$ & 27.6 & $>400$ & $>400$ & 200.7 & $>333.6$ & 115.1 & $><0.9$ & $><1$ & $><0.2$ & $><0.3$ \\
\hline 3 & $>400$ & $>400$ & $>400$ & $>400$ & $>400$ & & $>400$ & 388.5 & 385.2 & $>391.2$ & 7.8 & $><1$ & $><1$ & $><0.2$ & $><0.3$ \\
\hline 4 & 155.2 & 140.9 & 114.8 & 119.3 & 132.6 & 18.9 & 144.8 & 242.2 & 201.4 & 196.1 & 48.9 & 1.5 & 0.9 & 1.1 & 0.6 \\
\hline 5 & 100.4 & 136.3 & 124.3 & 87.6 & 112.1 & 22.1 & 322.3 & 244.6 & 180.4 & 249.1 & 71.0 & 2.2 & 3.2 & 2.0 & 3.2 \\
\hline 6 & 55.8 & 139.4 & 32.6 & 37.9 & 66.4 & 49.6 & 348.5 & 224.3 & 240.3 & 271.0 & 67.6 & 4.1 & 6.2 & 6.1 & 11.2 \\
\hline 7 & 36.2 & 55.3 & 27.9 & 28.8 & 37.0 & 12.7 & 277.6 & 1380.1 & 181.1 & 612.9 & 666.1 & 16.5 & 7.7 & 44.7 & 21.2 \\
\hline 8 & 40.4 & 37.5 & 34.4 & 32.2 & 36.1 & 3.6 & 86.1 & 59.1 & 40.3 & 61.8 & 23.0 & 1.7 & 2.1 & 4.7 & 5.3 \\
\hline DXR & 9.9 & $>400$ & $>400$ & $>400$ & $>302$ & 195.0 & $>400$ & 78.5 & $>400$ & $>292.8$ & 185.6 & $><1$ & $>40.3$ & $><0.3$ & $>406.9$ \\
\hline
\end{tabular}

$\mathrm{CC}_{50}$ value was determined by dose-response study, which was done in triplicate. Ca9-22, HSC-2, HSC-3 and HSC-4: Oral squamous cell carcinoma cell lines; HGF: human gingival fibroblasts; HPLF: periodontal ligament fibroblasts; HPC: pulp cells; $\mathrm{CC}_{50}$ : $50 \%$ cytotoxic concentration, DXR: doxorubicin; TS: tumor-selectivity index; PSE: potency-selectivity expression.

index and chemical descriptors was investigated using simple regression analyses by JMP Pro version 12.2.0 (SAS Institute Inc., Cary, NC, USA).

\section{Results}

Cytotoxicity. Ten azulene amide derivatives used in this study were classified into four categories, having $N$-alkyl [1-3], hydroxylalkyl $[4,5]$, methoxyalkyl $[6,7]$ and aminoalkyl
[8 10] groups at the end of carboxamide (Figure 1). We investigated their cytotoxic activity against four human oral squamous cell carcinoma (OSCC) cell lines (Ca9-22, HSC-2, HSC-3, HSC-4) and three normal oral cells (HGF, HPLF, HPC). The results of three independent experiments (each doseresponse study was done in triplicate) are shown in Table I.

We first investigated their cytotoxicity against OSCC cell lines. Among $N$-propyl group, [1] having 2 methylene units 
Table II. Explanation of chemical descriptors that correlate with cytotoxicity to tumor cells, normal cells and tumor-specificity.

\begin{tabular}{|c|c|}
\hline Descriptor & Explanation \\
\hline dens & Mass density: molecular weight divided by van der Waals volume as calculated in the vol descriptor. \\
\hline density & Molecular mass density: Weight divided by vdw_vol $\left(\mathrm{amu} / \AA^{3}\right)$. \\
\hline h_logD & The octanol/water distribution coefficient at $\mathrm{pH} \overline{7}$. \\
\hline h_logP & $\begin{array}{l}\text { Log of the octanol/water partition coefficient using an } 8 \text { parameter model based on Hueckel Theory } \\
\text { with } \mathrm{r}^{2}=0.84, \mathrm{RMSE}=0.59 \text { on } 1,836 \text { molecules. The calculated value is that of the protonation state of the structure as drawn. }\end{array}$ \\
\hline h_logS & $\begin{array}{l}\text { Log of the aqueous solubility }(\mathrm{mol} / \mathrm{L}) \text { using a } 7 \text { parameter model based on Hueckel Theory with } \mathrm{r}^{2}=0.83 \text {, } \\
\text { RMSE }=0.85 \text { on } 1,708 \text { molecules. The calculated value is that of the protonation state of the structure as drawn. }\end{array}$ \\
\hline h_pKb & $\begin{array}{l}\text { The } \mathrm{pKb} \text { of the reaction that adds a proton from the ensemble of states with a hydrogen count equal to } \\
\text { the input structure; } 14 \text { is reported if there are no states with more hydrogens than the input. }\end{array}$ \\
\hline h_pstrain & $\begin{array}{l}\text { The strain energy }(\mathrm{kcal} / \mathrm{mol}) \text { needed to convert all protonation states into the input protonation state: } \\
(\mathrm{kT} \ln 10)\left(\mathrm{pC} 1+\log \operatorname{sum}\left\{10^{\wedge}-\mathrm{pCi}\right\}\right)\end{array}$ \\
\hline vsurf_CW3 & Capacity factor 3 in vsurf_descriptors which are similar to the VolSurf descriptors \\
\hline vsurf_CW4 & Capacity factor 4 in vsurf_ descriptors which are similar to the VolSurf descriptors \\
\hline vsurf_HB3 & H-bond donor capacity 3 in vsurf_descriptors which are similar to the VolSurf descriptors \\
\hline vsurf_ID1 & Hydrophobic interaction energy moment 1 in vsurf_descriptors which are similar to the VolSurf descriptors \\
\hline vsurf_ID3 & Hydrophobic interaction energy moment 3 in vsurf_descriptors which are similar to the VolSurf descriptors \\
\hline vsurf_ID4 & Hydrophobic interaction energy moment 4 in vsurf_ descriptors which are similar to the VolSurf descriptors \\
\hline vsurf_ID5 & Hydrophobic interaction energy moment 5 in vsurf_descriptors which are similar to the VolSurf descriptors \\
\hline vsurf_IW1 & Hydrophilic interaction energy moment 1 in vsurf_descriptors which are similar to the VolSurf descriptors \\
\hline vsurf_R & Surface rugosity in vsurf_descriptors which are similar to the VolSurf descriptors \\
\hline vsurf_Wp4 & Polar volume 4 in vsurf_descriptors which are similar to the VolSurf descriptors \\
\hline vsurf_Wp5 & Polar volume 5 in vsurf_descriptors which are similar to the VolSurf descriptors \\
\hline
\end{tabular}

showed the highest cytotoxicity (mean $\mathrm{CC}_{50}=>108,13.8,10.4$ $\mu \mathrm{M})$, and with the increase of methylene units to 3 or 4 , their cytotoxicity declined ( $>367,>236,>386 \mu \mathrm{M}$; >369, >272, $>386 \mu \mathrm{M}$ ), possibly due to the insolubility in culture medium. Hydroxylalkyl [4, 5], methoxyalkyl $[6,7]$ and aminoalkyl [8 10] groups showed intermediate range of cytotoxicity.

Cytotoxicity of all compounds against normal cells was lower than that against OSCC cell lines.

Tumor-specificity (TS). TS was determined by dividing the mean $\mathrm{CC}_{50}$ value towards three normal cells by the mean $\mathrm{CC}_{50}$ value towards four OSCC cell lines (D/B, Table I). Considering that HGF is the normal cell corresponding to cancer cell $\mathrm{Ca} 9$ 22 (both derived from gingival tissues), TS value was also generated by dividing the $\mathrm{CC}_{50}$ value towards HGF cells by the $\mathrm{CC}_{50}$ value towards $\mathrm{Ca} 9-22$ cells $(\mathrm{C} / \mathrm{A}$, Table I). Among ten compounds [1-10], [1] showed the highest tumor-specificity ( $\mathrm{TS}=><3.7,>28.9,37.0$ in $\mathrm{D} / \mathrm{B} ;>27.7,>22.3,>53.6$ in $\mathrm{C} / \mathrm{A}$ in three independent experiments), followed by [7] $(\mathrm{TS}=4.3$, 5.2, 16.5 in $\mathrm{D} / \mathrm{B} ; 3.7,5.6,7.7$ in $\mathrm{C} / \mathrm{A})$ and [6] (TS=4.3, 4.0, 4.1 in $\mathrm{D} / \mathrm{B} ; 4.3,3.3,6.2$ in $\mathrm{C} / \mathrm{A})$. These values are comparable with those of doxorubicin $(\mathrm{TS}=448.1,>5.7,><1$ in $\mathrm{D} / \mathrm{B} ; 4.1,1.1$, $>40.3$ in $\mathrm{C} / \mathrm{A}$ ). TS values of other compounds were $<4.6$ in $\mathrm{D} / \mathrm{B}$ and $<3.2$ in $\mathrm{C} / \mathrm{A}$ (Table I).

PSE value. In order to identify the most promising compounds in terms of both good potencies and selectively cytotoxic, the potency-selectivity expression (PSE) values were calculated. [1] showed much higher PSE value [ $><34,>209.1,>356.1$ in $\left(\mathrm{D} / \mathrm{B}^{2}\right) \times 100 ;>191.6,>124.8,>717.3$ in $\left.\left.\left(\mathrm{C} / \mathrm{A}^{2}\right) \times 100\right)\right]$, followed by [7] [9.6, 11.6, 44.7 in $\left(\mathrm{D} / \mathrm{B}^{2}\right) \times 100 ; 8.3,12.0,21.2$ in $\left.\left.\left(\mathrm{C} / \mathrm{A}^{2}\right) \times 100\right)\right]$ and [6] [6.6, 6.5, 6.1 in $\left(\mathrm{D} / \mathrm{B}^{2}\right) \times 100 ; 6.6,5.4$,

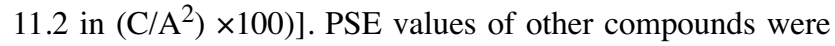
$<8.1$ in $\left(\mathrm{D} / \mathrm{B}^{2}\right) \times 100$ and $<5.3$ in $\left(\mathrm{C} / \mathrm{A}^{2}\right) \times 100$.

Western blot analysis demonstrated that $[\mathbf{1}, \mathbf{6}, \mathbf{7}]$ induced the cleavage of poly ADP-ribose polymerase and caspase-3, suggesting the induction of apoptosis (21) (Figure 2).

Computational analysis. Since [2] and [3] showed very low cytotoxicity $\left(\mathrm{CC}_{50}>400 \mu \mathrm{M}\right)$ in most cells, producing noise in QSAR analysis, we performed the QSAR analysis of eight azulene amide derivatives omitting [2] and [3], in regards to their cytotoxicity against tumor cells and normal cells. Among a total of 297 MOE descriptors), 18 descriptors correlated well with cytotoxicity and tumor specificity (Table III).

Cytotoxicity against human OSCC cell lines was correlated with dens (Molecular density) $\left(\mathrm{r}^{2}=0.835, p=0.0015\right)$, density (Molecular density) $\left(\mathrm{r}^{2}=0.824, p=0.0018\right)$, vsurf_R (Surface rugosity and shape) $\left(\mathrm{r}^{2}=0.764, \quad p=0.0045\right), \quad \mathrm{h} \_\log \mathrm{P}$ (Hydrophobicity) $\left(\mathrm{r}^{2}=0.689, p=0.0108\right)$, h_logS (Watersolubility) $\left(\mathrm{r}^{2}=0.683, p=0.0114\right)$, vsurf_HB3 (Hydrogen bond and shape) $\left(\mathrm{r}^{2}=0.681, p=0.0117\right)$ (Figure 3$)$.

Cytotoxicity against human normal oral mesenchymal cells was correlated with $\mathrm{h} \_$pstrain (Strain energy) $\left(\mathrm{r}^{2}=0.878\right.$, 
Ca9-22

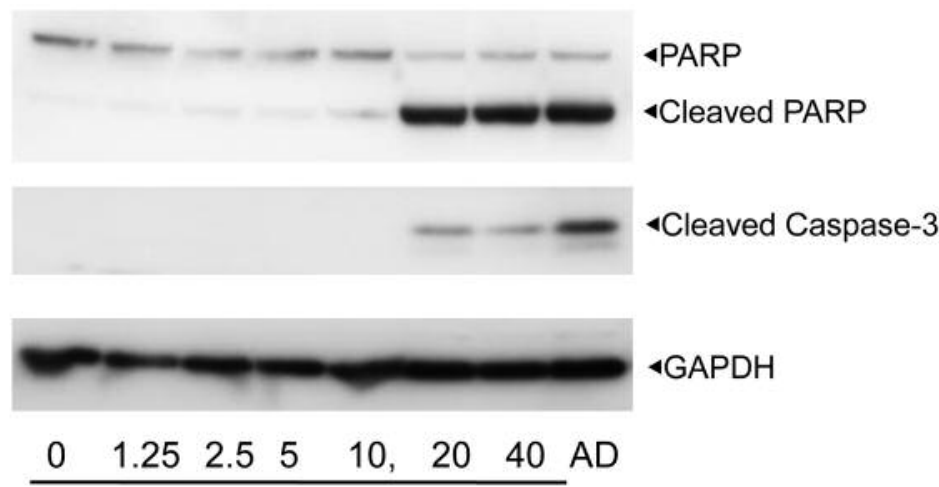

[1] $(\mu \mathrm{M})$

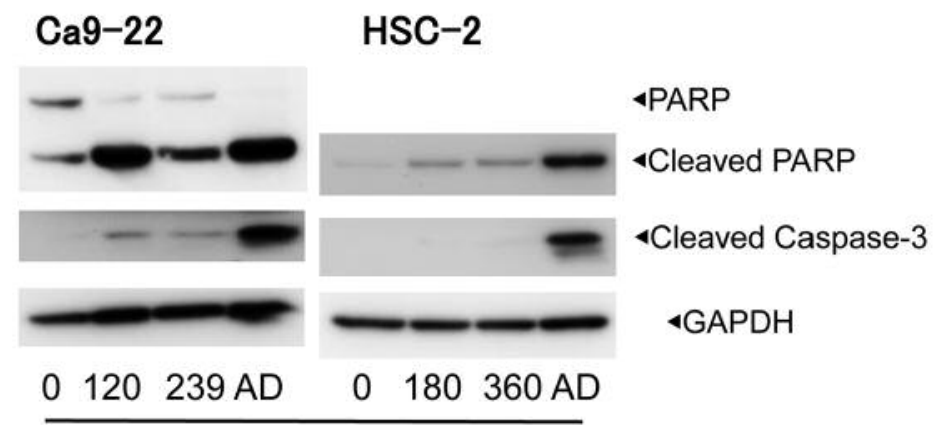

HSC-2

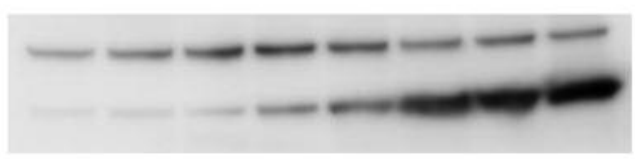

\section{3}
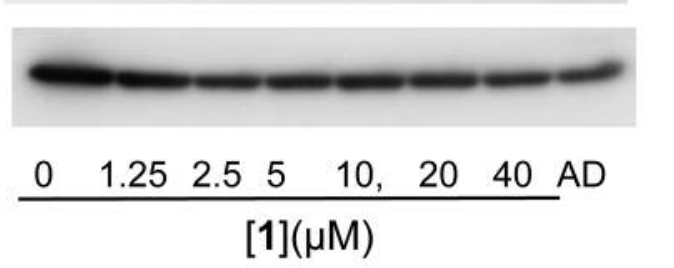

Ca9-22 HSC-2

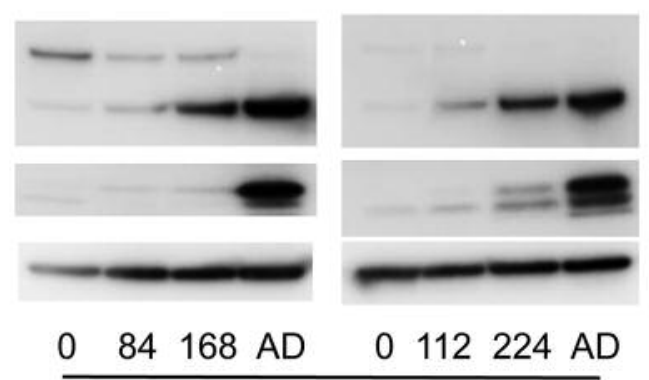

[7]( $\mu \mathrm{M})$

Figure 2. Apoptosis induction by [1, 6, 7] in Ca9-22 and HSC-2 human oral squamous cell carcinoma cell lines. AD: Actinomycin D (1 $\mu M)$.

$p=0.0006), \mathrm{h} \_\log \mathrm{D}$ (Hydrophobicity) $\left(\mathrm{r}^{2}=0.859, p=0.0009\right)$, vsurf_Wp5 (Polarity and shape) $\left(\mathrm{r}^{2}=0.818, p=0.0020\right)$, $\mathrm{h} \_\mathrm{pKb}$ (Dissociation constant) $\left(\mathrm{r}^{2}=0.817, \quad p=0.0020\right)$, vsurf_IW1 (Hydrophilicity and shape) $\left(\mathrm{r}^{2}=0.815, p=0.0021\right)$ and vsurf_Wp4 (Polarity and shape) $\left(\mathrm{r}^{2}=0.809, \mathrm{R}=0.0024\right)$ (Figure 4).

Tumor specificity was correlated with vsurf_ID1 (Hydrophobicity and shape) $\left(\mathrm{r}^{2}=0.931, p=0.0001\right)$, vsurf_ID5 (Hydrophobicity and shape) $\left(\mathrm{r}^{2}=0.918, p=0.0002\right)$, vsurf_ID4 (Hydrophobicity and shape) $\left(\mathrm{r}^{2}=0.869, p=0.0007\right)$, vsurf_CW4 (shape) $\left(\mathrm{r}^{2}=0.852, p=0.0011\right)$, vsurf_ID3 (Hydrophobicity and shape) $\left(\mathrm{r}^{2}=0.823, \quad p=0.0019\right)$ and vsurf_CW3 (shape) $\left(\mathrm{r}^{2}=0.818, p=0.0020\right)$ (Figure 5).

\section{Discussion}

The present study demonstrated that among ten azulene amide derivatives, $N$-propylguaiazulenecarboxamide [1] showed the highest in vitro antitumor activity, based on its greatest TS and PSE values and apoptotic-induced activity
Table III. Properties of descriptors that significantly affect the cytotoxicity against tumor cells $(T)$, normal cells $(N)$ and tumor-specificity $(T-N)$.

\begin{tabular}{lcccc}
\hline & Descriptors & Meaning & $\mathrm{r}^{2}$ & $p$-Value \\
\hline $\mathrm{T}$ & dens & Molecular density & 0.835 & 0.0015 \\
$\mathrm{~T}$ & density & Molecular density & 0.824 & 0.0018 \\
$\mathrm{~T}$ & vsurf_R & Surface rugosity and shape & 0.764 & 0.0045 \\
$\mathrm{~T}$ & h_logP & Hydrophobicity & 0.689 & 0.0108 \\
$\mathrm{~T}$ & h_logS & Water-solubility & 0.683 & 0.0114 \\
$\mathrm{~T}$ & vsurf_HB3 & Hydrogen bond and shape & 0.681 & 0.0117 \\
$\mathrm{~N}$ & h_pstrain & Strain energy & 0.878 & 0.0006 \\
$\mathrm{~N}$ & h_logD & Hydrophobicity & 0.859 & 0.0009 \\
$\mathrm{~N}$ & vsurf_Wp5 & Polarity and shape & 0.818 & 0.0020 \\
$\mathrm{~N}$ & h_pKb & Dissociation constant & 0.817 & 0.0020 \\
$\mathrm{~N}$ & vsurf_IW1 & Hydrophilicity and shape & 0.815 & 0.0021 \\
$\mathrm{~N}$ & vsurf_Wp4 & Polarity and shape & 0.809 & 0.0024 \\
$\mathrm{~T}-\mathrm{N}$ & vsurf_ID1 & Hydrophobicity and shape & 0.931 & 0.0001 \\
$\mathrm{~T}-\mathrm{N}$ & vsurf_ID5 & Hydrophobicity and shape & 0.918 & 0.0002 \\
T-N & vsurf_ID4 & Hydrophobicity and shape & 0.869 & 0.0007 \\
T-N & vsurf_CW4 & Shape & 0.852 & 0.0011 \\
T-N & vsurf_ID3 & Hydrophobicity and shape & 0.823 & 0.0019 \\
T-N & vsurf_CW3 & Shape & 0.818 & 0.0020 \\
\hline
\end{tabular}



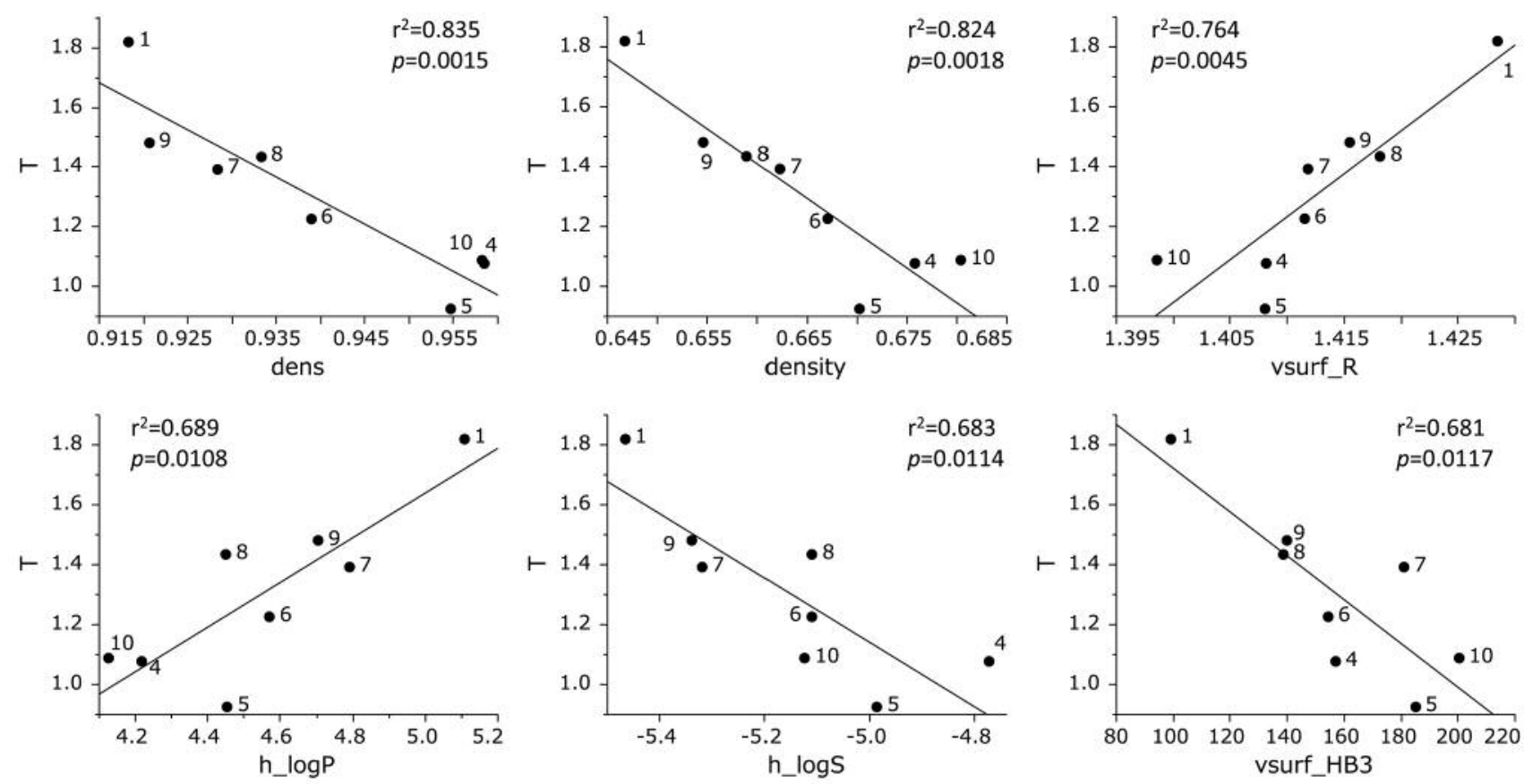

Figure 3. Determination of coefficient between chemical descriptors and cytotoxicity of eight azulene amide derivatives against tumor cells (defined as $T$ ). The mean ( $\mathrm{CC}_{50}$ i.e., the $-\log C C_{50}$ ) values for tumor cell lines were defined as $T$.
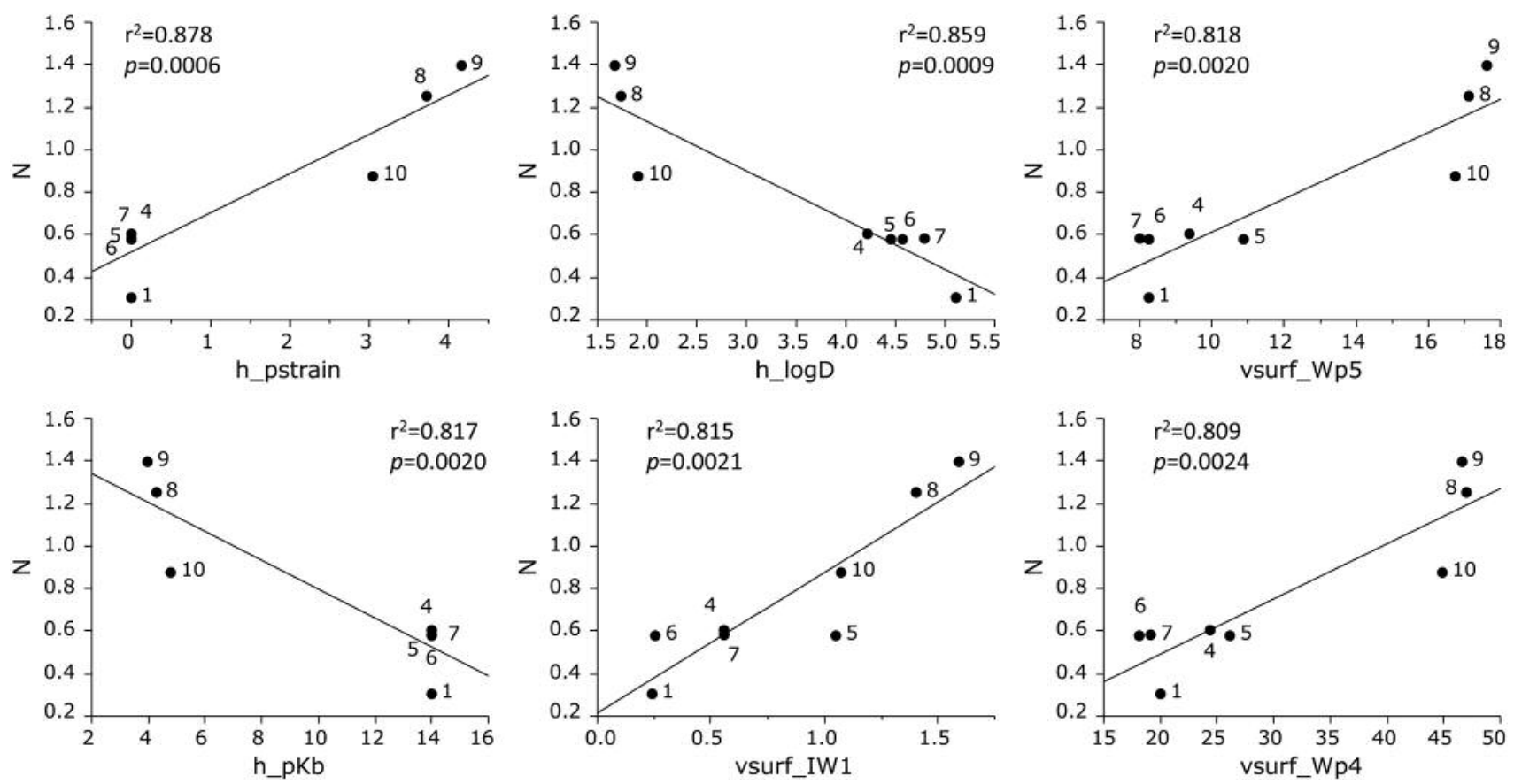

Figure 4. Determination of coefficient between chemical descriptors and cytotoxicity of eight azulene amide derivatives against normal cells (defined as $\mathrm{N}$ ). The mean $\left(\mathrm{pCC}_{50}\right.$ i.e., the $\left.-\log C C_{50}\right)$ values for normal cells were defined as $\mathrm{N}$. 

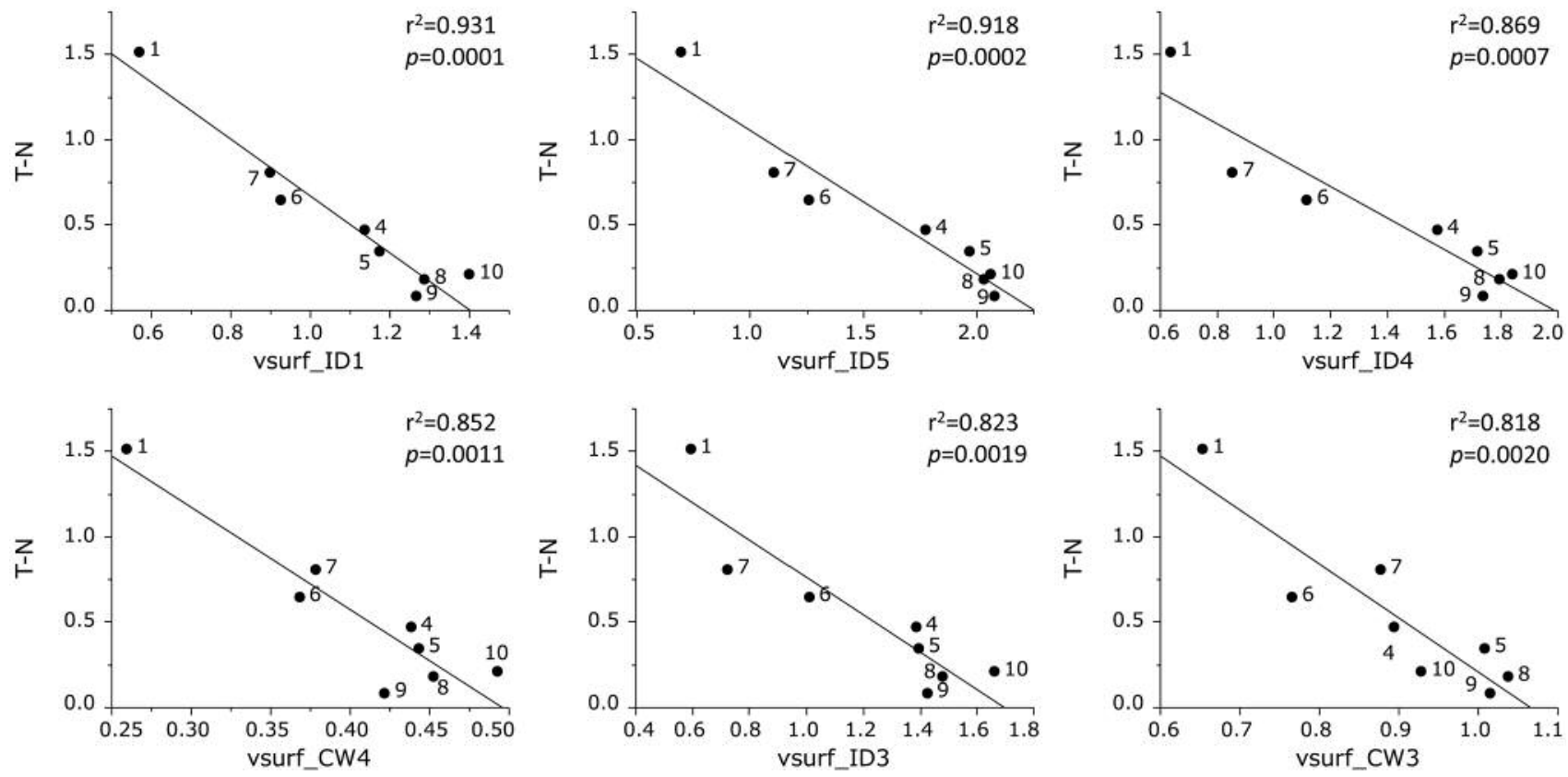

Figure 5. Determination of coefficient between chemical descriptors and tumor specificity of eight azulene amide derivatives (defined as T-N).

against two of OSCC cell lines. It was unexpected that [2] and [3], which have longer methylene units, showed much lower cytotoxicity against OSCC cell lines. This may be due to the insolubility of these compounds in the culture medium. By omitting these two compounds, we found a good association of TS value and hydrophobicity. If the solubility of [2] and [3] is improved, TS value of these compounds may be much improved.

QSAR analysis demonstrated that [1] exhibited the highest value of 6 chemical descriptors (hydrophobicity and molecular shape) that correlated with TS value (Figure 5). We also confirmed that $[6,7]$, that ranked at the second and third position of TS values, also had high scores in these parameters (Figure 5).

On the other hand, $[\mathbf{8}, \mathbf{9}, \mathbf{1 0}]$, having an amino group at the terminal and intermediate score of hydrophobicity (Figure 3), showed the highest cytotoxicity against normal cells (Figure 4) and lowest tumor specificity (Figure 5).

Taken together, the present study suggests that compound [1] can be considered as a lead compound for manufacturing new anticancer drug candidates.

\section{Conflicts of Interest}

The Authors confirm that there are no known conflicts of interest associated with this publication and there was no significant financial support for this work that could have influenced its outcome.

\section{Acknowledgements}

This work was partially supported by KAKENHI from the Japan Society for the Promotion of Science (JSPS) (16K11519).

\section{References}

1 Kalil DM, Silvestro LS and Austin PN: Novel preoperative pharmacologic methods of preventing postoperative sore throat due to tracheal intubation. AANA J 82(3): 188-197, 2014.

2 Sakai $\mathrm{H}$ and Misawa M: Effect of sodium azulene sulfonate on capsaicin-induced pharyngitis in rats. Basic Clin Pharmacol Toxicol 96(1): 54-59, 2005.

3 Ge ZD, Auchampach JA, Piper GM and Gross GJ: Comparison of cardioprotective efficacy of two thromboxane A2 receptor antagonists. J Cardiovasc Pharmacol 41(3): 481-488, 2003.

4 Kourounakis AP, Rekka EA and Kourounakis PN: Antioxidant activity of guaiazulene and protection against paracetamol hepatotoxicity in rats. J Pharm Pharmacol 49(9): 938-942, 1997.

5 Kourounakis AP, Rekka EA and Kourounakis PN: Effect of guaiazulene on some cytochrome $\mathrm{P} 450$ activities. Implication in the metabolic activation and hepatotoxicity of paracetamol. Arch Pharm (Weinheim) 330(1-2): 7-11, 1997.

6 Li P, Liu X, Zhu H, Tang X, Shi X, Liu Y and Li G: Unusual Innersalt guaiazulene alkaloids and bis-sesquiterpene from the South China Sea Gorgonian Muriceides collaris. Sci Rep 7(1): 7697, 2017.

7 Wakabayashi H, Hashiba K, Yokoyama K, Hashimoto K, Kikuchi H, Nishikawa H, Kurihara T, Satoh K, Shioda S, Saito S, Kusano S, Nakashima H, Motohashi $\mathrm{N}$ and Sakagami H: Cytotoxic activity of azulenes against human oral tumor cell lines. Anticancer Res 23(6C): 4747-4755, 2003. 
8 Togar B, Turkez H, Hacimuftuoglu A, Tatar A and Geyikoglu F: Guaiazulene biochemical activity and cytotoxic and genotoxic effects on rat neuron and N2a neuroblastom cells. J Intercult Ethnopharmacol 4(1): 29-33, 2015.

9 Fiori J, Teti G, Gotti R, Mazzotti G and Falconi M: Cytotoxic activity of guaiazulene on gingival fibroblasts and the influence of light exposure on guaiazulene-induced cell death. Toxicol In Vitro 25(1): 64-72, 2011.

10 Hannun YA: Apoptosis and the dilemma of cancer chemotherapy. Blood 89(6): 1845-1853, 1997.

11 Doukas PH and Speaker TJ: Azulene analogs of pharmacologic agents I: amides. J Pharm Sci 60: 184-189, 1971.

12 Toyama Y, Miyazawa S and Yokota M: Azulenes, their preparation, and antibacterial agents containing them. Jpn Kokai Tokkyo Koho JP 2004217602 A 20040805, 2004.

13 Anderson, AG, Anderson RG and Fujita TS: Displacement reactions on 1-azulylmethyltrimethylammonium iodide. J Org Chem 27: 4535-4539, 1962.

14 Mathias LJ and Overberger CG: Simple syntheses of 1,3bis(perfluoroacethyl)azulene and 1,3-azulenedicarboxylic acid. J Org Chem 45: 1702-1703, 1980.

15 Kantoh K, Ono M, Nakamura Y, Nakamura Y, Hashimoto K, Sakagami $\mathrm{H}$ and Wakabayashi H: Hormetic and anti-radiation effects of tropolone-related compounds. In Vivo 24: 843-852, 2010.

16 Uesawa Y, Sakagami H, Ishihara M, Kagaya H, Kanamoto T, Terakubo S, Nakashima H, Yahagi H, Takao K and Sugita Y: Quantitative structure-cytotoxicity relationship of 3-styryl-2Hchromenes. Anticancer Res 35: 5299-5308, 2015.
17 Horikoshi M, Kimura Y, Nagura H, Ono T and Ito H: A new human cell line derived from human carcinoma of the gingiva. I. Its establishment and morphological studies. Jpn J Oral Maxillofac Surg 20: 100-106, 1974.

18 Sakagami H, Okudaira N, Masuda Y, Amano O, Yokose S, Kanda $Y$, Suguro M, Natori T, Oizumi $H$ and Oizumi T: Induction of apoptosis in human oral keratinocyte by doxorubicin. Anticancer Res 37(3): 1023-1029, 2017.

19 Tomikoshi Y, Nomura M, Okudaira N, Sakagami H and Wakabayashi H: Enhancement of cytotoxicity of three apoptosisinducing agents against human oral squamous cell carcinoma cell line by benzoxazinotropone. In Vivo 30(5): 645-650, 2016.

20 Cruciani G, Crivori P, Carrupt P-A and Testa B: Molecular fields in quantitative structure-permeation relationships: the VolSurf Approach. Mol Struct (Theochem) 503: 17-30, 2000.

21 Bressenot A, Marchal S, Bezdetnaya L, Garrier J, Guillemin F and Plénat F: Assessment of apoptosis by immunohistochemistry to active caspase-3, active caspase-7, or cleaved PARP in monolayer cells and spheroid and subcutaneous xenografts of human carcinoma. J Histochem Cytochem 57(4): 289-300, 2009.

Received February 10, 2018

Revised March 6, 2018

Accepted March 7, 2018 